\begin{tabular}{l}
\hline RECORDS OF PHARMACEUTICAL \\
AND BIOMEDICAL SCIENCES
\end{tabular}

\title{
The Possible Protective Effects and Mechanisms of Action of Pycnogenol: In Vivo Animals and Human Studies
}

\author{
Faten A. M. Al-Abkal, Dina M. Khodeer, Yasser M.A. Moustafa \\ ${ }^{a}$ Department of Pharmacology \& Toxicology, Faculty of Pharmacy, Suez Canal University, Ismailia, 41522, \\ Egypt
}

Received on: 15. 07. 2021

Revised on: 27. 072021

Accepted on: 30. 07. 2021

*Correspondence Author:

Tel: $+2-01149681599$

E-mail address:

fatenalabkal@gmail.com

\begin{abstract}
Pycnogenol (PYC) is a plant-based extract derived from the proprietary bark of the French maritime pine (Pinus pinaster ssp. atlantica) that exerts antioxidative, anti-inflammatory, and anti-platelet effects. The standardized extract is composed of phenolic compounds (catechin, epicatechin, and taxifolin), condensed flavonoids (classed as procyanidins/ proanthocyanidins) and phenolic acids (cinnamic acids and other glycosides). These phenolic compounds after being ingested, undergo biotransformation and are broken down in the colon by microbial enzymes yielding smaller, bioavailable molecules that can then be absorbed by the colon into the bloodstream and transported to tissues and organs. The pycnogenol possess a highly protective characteristics versus various cardiovascular dysfunctions, kidney diseases, hepatic dysfunctions, neuro cognitive disorder, diabetes, reproductive dysfunction and infertility, cancer, digestive, retinal disease. The present review illustrates the effect of Pycnogenol as antioxidant and anti-inflammatory effects along with anti-tumor influence as well. Pycnogenol was concluded to act as an antioxidant agent in different situation including heart stress, cardiovascular system abnormalities, kidney disease and hepatic disorders, so it can be used in combination with other medication such as Methotrexate to abolish its side effects.
\end{abstract}

Keywords: Pycnogenol, antioxidant, Pinus pinaster, cardiovascular dysfunctions, kidney diseases, hepatic dysfunctions, protective

\section{Introduction}

Pycnogenol is highly protective properties against several diseases such as cardiovascular dysfunctions, kidney diseases, hepatic dysfunctions, neuro cognitive disorder, diabetes, reproductive dysfunction and infertility, cancer, digestive, retinal disease (Weichmann and Rohdewald, 2020). Pycnogenol $\mathbb{R}$ is extracted from the bark of maritime pine trees (Pinus pinaster) originating from France. The result is a very fine, red/browncoloured, water-soluble powder. Pycnogenol $\mathbb{R}$ mainly contains procyanidins and their monomers (catechin and epicatechin) as well as phenolic acids. The total amount of procyanidins is standardized to $70 \pm 5 \%$. Pycnogenol $\mathbb{R}$ meets the 
specifications for maritime pine extract, detailed in the United States Pharmacopeia (USP). The procyanidins are biopolymers consisting of units of catechin and epicatechin, with most chain lengths of 2-12 monomeric units (Oliff, 2019; Weichmann and Rohdewald, 2020).

Pycnogenol $R$ is self-affirmed GRAS (Generally Recognized As Safe) for use in conventional foods, based on the evaluation of clinical safety and preclinical toxicology data by an independent panel of toxicology experts. Nonmutagenicity, lethal dose (LD50) $>5.0 \mathrm{~g} / \mathrm{kg}$ body weight, NOAEL > $1000 \mathrm{mg} / \mathrm{kg} /$ day have been determined (Oliff, 2019). Based on current European Food Safety Agency (EFSA) recommendations, this translates in a safe dosage of $>700 \mathrm{mg} /$ day. Typically, oral dosages tested in the literature are in the $30-200 \mathrm{mg} /$ day range, with some studies exploring higher dosages of 200-450 $\mathrm{mg}$ /day. Since it was introduced into the market in Europe around 1970, there have been no reports of serious adverse effects in any clinical study or from commercial use of Pycnogenol $\mathbb{R}$. Mild side-effects of gastric discomfort have rarely been reported and linked to stomach-sensitive patients. No interactions of Pycnogenol $\mathbb{R}$ with other drugs, alcohol or food intake have been reported (Oliff, 2019). Pycnogenol $\mathbb{R}$ ) does not affect INR (a measure of bleeding tendency) or platelet function in patients taking aspirin (Oliff, 2019). One University study evaluated patients $(n=28 ; 49-73$ years $)$ with stable coronary artery disease treated with both optimal standard therapy and $200 \mathrm{mg} /$ day Pycnogenol $\mathbb{R}$ for 8 weeks. Standard therapy included aspirin (100\% of patients), statins (87\%), ACE inhibitors/angiotensin receptor blockers $(78 \%), \beta$ blockers (74\%), diuretics (35\%), calcium antagonists (17\%), clopidogrel (17\%), ezetimibe $(17 \%)$, oral antidiabetics (17\%), phenprocoumon (4\%), and $\alpha$-antagonists (4\%). There were no adverse drug-herb interactions (Enseleit et al., 2012; Weichmann and Rohdewald, 2020).

\section{Description of Pycnogenol}

Pycnogenol (PYC) is a plant-based extract derived from the proprietary bark of the French maritime pine (Pinus pinaster ssp. atlantica) that exerts antioxidative, anti-inflammatory, and anti-platelet effects (Enseleit et al., 2012). It grows along the coastal southwest of France. Pine bark extracts have been used traditionally and date back at least to
Hippocrates (inflammation) around $400 \mathrm{BC}$ and Hans Minner around 1479 to treat wounds (Drehsen, 1999). The standardized extract is composed of phenolic compounds, divided between monomers (catechin, epicatechin, and taxifolin), condensed flavonoids (classed as procyanidins/ proanthocyanidins) and phenolic acids (cinnamic acids and other glycosides) (Petrassi et al., 2000; Rohdewald, 2004)(Figure 1).

After being ingested, these phenolic compounds undergo biotransformation and are broken down in the colon by microbial enzymes yielding smaller, bioavailable molecules that can then be absorbed by the colon into the bloodstream and transported to tissues and organs (Trebatická and Duračková, 2015). The nutritional preparation is extracted from crushed bark, followed by a patented extraction process (Rohdewald, 2002). The quality and purity of the raw bark are assessed by a French independent regulatory and control body, The French Association of Norms Association Française des Normes, AFNOR (Association Française des Normes, AFNOR: Packer et al., 1999) and conforms to the monograph "Maritime pine extract" in the United States Pharmacopeia (USP). PYC is available in most countries as an over-the-counter product, in tablet or capsule form in doses varying from 20 to $100 \mathrm{mg}$ (Rohdewald, 2002), and has demonstrated good tolerability with very few side effects and a high level of safety (Rohdewald, 2004).

Based on a recent update by the American Botanical Council of the Scientific and Clinical Monograph for Pycnogenol (The American Botanical Council, 2019), it is stated that an independent panel of toxicology experts has classified PYC as generally recognized as safe (GRAS) based on clinical safety and preclinical toxicology data. Additionally, while there are no known contraindications for PYC, it is recommended that children under 6 years of age should not use PYC, and PYC should not be taken during the first 3 months of pregnancy as a precaution. The data of 91 human clinical studies (6,849 people) have informed the safety PYC whereby the frequency of adverse events (AEs) is $2.4 \%$; and in healthy participants, the global AE rate is $0.1 \%$. Furthermore, the AEs reported in the clinical trials were unrelated to the duration of use or dose of PYC. The most commonly reported AE was gastrointestinal discomfort; it is therefore recommended that PYC is taken with food. Other reported AEs are dizziness, headache, and nausea. 
<smiles>Oc1cc(O)c2c(c1)O[C@H](c1ccc(O)c(O)c1)[C@H](O)C2c1c(O)cc(O)c2c1O[C@H](c1ccc(O)c(O)c1)[C@H](O)C2c1c(O)cc(O)c2c1O[C@H](c1ccc(O)c(O)c1)[C@H](O)C2</smiles>

Figure 1. Structure of a procyanidin molecule consisting of catechin and epicatechin subunits which are the main constituents of Pycnogenol (PYC). The catechin and epicatechin units can be linked by different bonds, the main being $\mathrm{C4}$-C8 bonds and $\mathrm{C4}-\mathrm{C} 6$ bonds as well as $\mathrm{C4}-\mathrm{C} 8$ bonds with different chain lengths up to dodecamers (Simpson et al., 2019).

The result is a very fine, red/brown-colored, watersoluble powder. Pycnogenol $\mathbb{R}$ mainly contains procyanidins and their monomers (catechin and epicatechin) as well as phenolic acids. The total amount of procyanidins is standardized to $70 \pm 5 \%$. Pycnogenol $\mathbb{R}$ meets the specifications for maritime pine extract, detailed in the United States Pharmacopeia (USP). The procyanidins are biopolymers consisting of units of catechin and epicatechin, with most chain lengths of 2-12 monomeric units (Oliff, 2019; Weichmann and Rohdewald, 2020).

\section{Safety and toxicity}

Pycnogenol $\mathbb{R}$ is self-affirmed GRAS (Generally Recognized As Safe) for use in conventional foods, based on the evaluation of clinical safety and preclinical toxicology data by an independent panel of toxicology experts. Non-mutagenicity, lethal dose $(\mathrm{LD} 50)>5.0 \mathrm{~g} / \mathrm{kg}$ body weight, NOAEL > $1000 \mathrm{mg} / \mathrm{kg} /$ day have been determined (Oliff, 2019). Based on current European Food Safety Agency (EFSA) recommendations, this translates in a safe dosage of $>700 \mathrm{mg} /$ day. Typically, oral dosages tested in the literature are in the 30-200 $\mathrm{mg} /$ day range, with some studies exploring higher dosages of 200-450 mg/day. Since it was introduced into the market in Europe around 1970, there have been no reports of serious adverse effects in any clinical study or from commercial use of Pycnogenol $\mathbb{R}$. Mild side-effects of gastric discomfort have rarely been reported and linked to stomach-sensitive patients. No interactions of Pycnogenol $\mathbb{R}$ with other drugs, alcohol or food intake have been reported (Oliff, 2019).

Pycnogenol $(\mathbb{R}$ does not affect INR (a measure of bleeding tendency) or platelet function in patients taking aspirin (Oliff, 2019). One University study evaluated patients ( $\mathrm{n}=28 ; 49-73$ years) with stable coronary artery disease treated with both optimal standard therapy and $200 \mathrm{mg} /$ day Pycnogenol $\mathbb{R}$ for 8 weeks. Standard therapy included aspirin (100\% of patients), statins (87\%), ACE inhibitors/angiotensin receptor blockers $(78 \%), \beta$ blockers (74\%), diuretics $(35 \%)$, calcium antagonists (17\%), clopidogrel (17\%), ezetimibe $(17 \%)$, oral antidiabetics $(17 \%)$, phenprocoumon (4\%), and $\alpha$-antagonists (4\%). There were no adverse drug-herb interactions (Enseleit et al., 2012; Weichmann and Rohdewald, 2020).

\section{Clinical Effects of Pycnogenol}

\subsection{Improvement of endothelial health}

Several clinical studies with patients having no or particular comorbidities showed that Pycnogenol $\mathbb{R}$ can improve endothelial function (Enseleit et al., 2012; Nishioka et al., 2007; Weichmann and Rohdewald, 2020; Zibadi et al., 2008). The suggested mechanism of action is activation of the endothelial nitric oxide synthase (eNOS), thus amplifying the NO generation from L-arginine, eventually leading to an increase in vessel lumen and adequate tissue perfusion. In patients with coronary artery disease, endothelial function was assessed by measuring the flow-mediated dilatation (FMD) of the brachial artery; $200 \mathrm{mg}$ Pycnogenol $(\mathbb{R})$ per day was supplemented in a randomized, double-blind, placebo-controlled cross-over study for 8 weeks (Enseleit et al., 2012). FMD during supplementation was improved by $33 \%$, whereas FMD slightly decreased during placebo (Enseleit et al., 2012). 
In a double-blind placebo-controlled randomized study with hypertensive patients, endothelin-1 which acts as a vasoconstrictor - was significantly lowered by $20 \%$ in the supplement group, whereas vasodilatory 6-keto prostaglandin F1a, the physiologically active and stable metabolite of prostacyclin, increased compared with the placebo group (Liu et al., 2004). This indicates improved endothelial function. The patients had been taking $100 \mathrm{mg}$ Pycnogenol $\mathbb{R}$ per day for 12 weeks (Liu et al., 2004). Another double-blind, placebo-controlled study reported similar effects when supplementing type II diabetes and hypertensive patients, taking an ACE inhibitor together with $125 \mathrm{mg}$ Pycnogenol $\mathbb{R}$ daily for 3 months. Here, the serum endothelin-1 levels were lowered by $17.8 \%$ compared with scarcely any change in placebo patients (Zibadi et al., 2008).

Nishioka et al. investigated the pharmacological effects of Pycnogenol $\mathbb{R}$ on the endotheliumdependent vasodilation via NO production by measuring the forearm blood flow in response to acetylcholine (an endothelium-dependent vasodilator) (Nishioka et al., 2007). Following 200 $\mathrm{mg}$ Pycnogenol $\mathbb{R}$ intake per day for 14 days, forearm blood flow in response to acetylcholine of healthy volunteers significantly increased up to $41 \%$ (Nishioka et al., 2007). As a negative control, the forearm blood flow was also measured in response to an endothelium independent vasodilator (sodium nitroprusside), which showed no change after Pycnogenol $\mathbb{R}$ intake compared with the placebo group. In this study, healthy individuals were supplemented with placebo or $180 \mathrm{mg}$ Pycnogenol $(R)$ per day for 2 weeks in a double-blinded fashion. This is a confirmation of the beneficial effects of Pycnogenol $\mathbb{R}$ ) on endothelial function (Nishioka et al., 2007).

Several studies reported that the efficiency of Pycnogenol $\mathbb{R}$ on blood vessels depends on the endothelium, as it could be abolished by administration of an endothelium-specific NO synthase inhibitor or by removing the endothelial lining (Fitzpatrick et al., 1998; Nishioka et al., 2007). These findings suggest that Pycnogenol $\mathbb{R}$ acts by increasing NO production in the endothelium, which in turn leads to better perfusion and blood circulation within vessels (Nishioka et al., 2007). As mentioned before (1.2), SARS-CoV2 strongly affects endothelial cells, triggering an inflammation and/or coagulopathies and leading to endothelial activation and pro-thrombotic conditions. Regarding endotheliitis, Pycnogenol $\mathbb{R}$ studies offer good evidence for potential beneficial effects for different patients to improve endothelial function.

\subsection{Improvement of microcirculation}

Insufficient microcirculation is observed in diabetes, hypertension or cardiovascular and lung diseases. Pycnogenol $\mathbb{R}$ has been shown to improve this condition by strengthening the microcirculation perfusion system (Belcaro et al., 2006). The microcirculation in fingernails, for instance, was determined by measuring the diameter of micro-vessels, which improved in patients treated with Pycnogenol $\mathbb{R}$ compared with placebo treatment. In two clinical studies, the transcutaneous PO2 and PCO2 levels as well as the flux at rest and the level of venoarteriolar response were measured to investigate the effects of Pycnogenol $\mathbb{R}$ on microcirculation in patients with microangiopathy resulting from diabetes or chronic venous insufficiency (Belcaro et al., 2006, 2005). The PO2 levels increased, whereas the PCO2 levels decreased compared with control patients upon

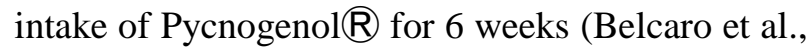
2006). The flux at rest was lower than at inclusion and the level of venoarteriolar response significantly increased upon supplementation (Belcaro et al., 2006). Another measure for capillary leaking is the strain-gauge-derived rate of ankle swelling, which was significantly reduced after supplementation with Pycnogenol $\mathbb{R}$ in diabetic patients with microangiopathy (Cesarone et al., 2006).

Tissue health is tightly connected to the strength of capillary walls. Increased capillary wall strength

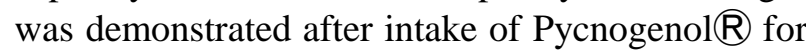
3 months in a clinical study with diabetic patients suffering from retinopathy (Steigerwalt et al., 2009). Here, retinal oedema, assessed by measuring the retinal thickness, was significantly reduced in patients taking $150 \mathrm{mg}$ Pycnogenol $\mathbb{R}$ per day. This resulted in improved visual acuity in the supplemented subjects, whereas it was unchanged in control patients. In severe cases of retinopathy, dysfunctional retinal capillaries can leak, which eventually leads to irreversible vision loss. This study suggested that Pycnogenol $\mathbb{R}$ can counteract capillary leaking by strengthening the capillary walls (Steigerwalt et al., 2009). Capillary leak 
syndrome is characterized by hyperpermeable capillaries through disruption of endothelial cell-tocell binding, which results in diffusion of blood plasma into surrounding tissues or interstitial spaces (Baluna et al., 1999; Kawabe et al., 2002; Siddall et al., 2017).

In most cases, acute kidney injury or nephritis and severe capillary leak syndrome are found together (Kawabe et al., 2002). Pycnogenol $\mathbb{R}$ supplementation has also been shown to improve kidney function in metabolic-syndrome patients with micro-albuminuria and in hypertensive patients with early signs of renal function impairment (Cesarone et al., 2010; Stuard et al., 2010). Urinary albumin levels significantly decreased and kidney cortical blood flow increased in patients taking Pycnogenol $\mathbb{R}$ in addition to an ACE inhibitor, compared with subjects medicated only with the ACE inhibitor for 6 months (Cesarone et al., 2010; Stuard et al., 2010). Pycnogenol $\mathbb{R}$ has the potential to act favorably and bring microcirculation to normal levels (Weichmann and Rohdewald, 2020).

\subsection{Platelet reactivity}

The activation and subsequent aggregation of blood platelets can lead to severe, life-threatening conditions like thrombosis, stroke or heart attack. By increasing the production of endothelial NO, Pycnogenol $\mathbb{R}$ has the ability to lower blood platelet aggregation as effectively as aspirin, without increasing the bleeding time (Araghi-Niknam et al., 2000; Pütter et al., 1999). In individuals with increased blood platelet activity - such as smokers Pycnogenol $\mathbb{R}$ has been shown to act dosedependently on platelet aggregation (AraghiNiknam et al., 2000; Pütter et al., 1999). This smoke-induced platelet aggregation was reduced to the level of non-smokers after supplementation with $200 \mathrm{mg}$ Pycnogenol $\mathbb{R}$ per day for 2 months (Araghi-Niknam et al., 2000). This effect was not observed in healthy non-smokers; hence, Pycnogenol $\mathbb{R}$ normalized pathologically increased platelet activity, but did not further decrease normal platelet function (Araghi-Niknam et al., 2000). Pycnogenol $\mathbb{R}$ prevented platelet hyperactivity but is safe, as it did not influence bleeding time, unlike aspirin, which significantly increased the time of bleeding from 167 to 236 seconds (Pütter et al., 1999). These results suggest that Pycnogenol $\mathbb{R}$ acts on platelet aggregation as effectively as aspirin, but without increasing the risk of bleeding complications (Pütter et al., 1999).

It has been confirmed in a university study that Pycnogenol $\mathbb{R}$ does not further decrease platelet activity in cardiovascular patients taking aspirin (Enseleit et al., 2012).

\subsection{Anti-inflammatory antioxidative aspects}

and

Intrusion of viruses, bacteria or other pathogens activates inflammatory cascades and pathways, like the $\mathrm{NF}-\mathrm{kB}$ (nuclear factor kappa-light-chainenhancer of activated B cells) pathway, resulting in the release of inflammatory mediators such as TNF- $\alpha$ and the interleukins IL-1 and IL-6 (Medzhitov, 2008). During an inflammation, a number of reactive oxygen species are produced, which in turn fuel the inflammasome, leading to the secretion of interleukins (Mittal et al., 2014). The antioxidant activity of Pycnogenol $\mathbb{R}$ has been investigated in a number of clinical studies (Chovanová et al., 2006; Devaraj et al., 2002; Enseleit et al., 2012; Kashevarova et al., 2018; Ryan et al., 2008). Orally administered Pycnogenol ${ }^{\circledR}$ has been shown to both increase the plasma antioxidant capacity, expressed as oxygen radical absorbance capacity (Devaraj et al., 2002), and decrease the plasma oxidative stress measured as plasma free radicals (Belcaro et al., 2006). Pycnogenol $\mathbb{R}$ has further been shown to protect lipids from peroxidation by free radicals in elderly people and people with coronary artery disease (Enseleit et al., 2012; Ryan et al., 2008).

The protective effect of Pycnogenol $\mathbb{R}$ on DNA oxidation was shown in a randomized, doubleblind, placebo-controlled study of children with ADHD, by measuring the level of oxidised purines (Chovanová et al., 2006). The anti-inflammatory activity of Pycnogenol $\mathbb{R}$ has been observed in many studies (Canali et al., 2009; Grimm et al., 2006; Schäfer et al., 2006; Xia et al., 2015). To investigate the underlying mechanism in a context close to physiology, ex-vivo approaches have been developed, in which healthy volunteers were supplemented with Pycnogenol $\mathbb{R}$ and blood samples were taken after a specific time (Schäfer et al., 2006, p. 2; Xia et al., 2015).

The respective serum/plasma samples contain bioactive molecules and can be used in cell culture studies as active ingredients and be compared with plasma before supplementation (Schäfer et al., 2006, p. 2; Xia et al., 2015). Thus, by taking into 
account the process of absorption, distribution and gut metabolism, the molecular pharmacological mechanisms of complex plant extracts can be investigated in a more rational way compared with in vitro studies (Grimm et al., 2006). To induce inflammation ex vivo, leucocytes are primed with endotoxins such as lipopolysaccharides, which are present on the outer membrane of Gram-negative bacteria, triggering a strong immune response (Raetz and Whitfield, 2002).

In addition, the leucocytes can be stimulated with formyl-methionyl-leucyl-phenylalanine (fMLP) to activate the arachidonic acid cascade, a pathway involved in inflammation, whereby cyclooxygenase (COX) enzymes 1 and 2, and 5-lipoxygenase (5LOX) metabolise arachidonic acid to prostaglandins, prostacyclin, thromboxanes and leukotrienes (Hanna and Hafez, 2018). After intake of $150 \mathrm{mg}$ Pycnogenol $\mathbb{R}$ per day for 5 days, the serum of volunteers decreased 5-LOX and COX-2 gene up-regulation and fMLP-enhanced leukotriene biosynthesis in an ex vivo study using polymorphonuclear leukocytes (Canali et al., 2009). Another ex vivo study employed plasma from healthy individuals consuming $200 \mathrm{mg}$ Pycnogenol $(R)$ per day for 5 days, which was incubated with monocytes and subsequently with LPS to induce inflammation (Grimm et al., 2006). Plasma samples obtained after intake of Pycnogenol $\mathbb{R}$ statistically significantly inhibited matrix metalloproteinase 9 (MMP-9) release from human monocytes and NF$\kappa \mathrm{B}$ activation as compared with control plasma samples before supplementation (Grimm et al., 2006).

The Pycnogenol $\mathbb{R}$ metabolite M1 $(\delta-(3,4-$ dihydroxy-phenyl)- $\gamma$-valerolactone), which undergoes facilitated uptake by monocytes, macrophages, erythrocytes and endothelial cells, was shown to exert direct anti-inflammatory activity by reducing iNOS (inducible nitric oxide synthase) expression and excessive nitrite production (Enseleit et al., 2012; Grimm et al., 2006; Kurlbaum et al., 2013). In a similar setup, statistically significant inhibition of COX-1 and COX-2 was observed with serum samples of the volunteers obtained 30 minutes after a single dose of $300 \mathrm{mg}$ Pycnogenol $\mathbb{R}$ (Schäfer et al., 2006).

In an animal-based study, the effects of Pycnogenol $(R)$ on ventilator-induced lung injury of rats - which generally involves excessive inflammation - were investigated (Xia et al., 2015). The production of pro-inflammatory cytokines, such as TNF- $\alpha$, IL-1 $\beta$, macrophage IL-6 and MIP-2 was reduced towards normal levels through the inhibition of NF- $\kappa B$ activation after administration of Pycnogenol $\mathbb{R}$. The authors suggested Pycnogenol $\mathbb{R}$ to be a potential therapeutic option for ventilator-induced injury (Xia et al., 2015). Hence, having antiinflammatory and antioxidative effects in addition to the beneficial effects on ventilator-induced injuries, Pycnogenol $\mathbb{R}$ presents two very important advantages. Additionally, there are hints that Pycnogenol $\mathbb{R}$ ) metabolites M1 ( $\delta$-(3,4-dihydroxyphenyl)- $\gamma$-valerolactone) and M2 ( $\delta$-(3-methoxy-4hydroxyphenyl)- $\gamma$-valerolactone) bind to zinc (2+) ions (Grimm et al., 2004). Zinc ions are known modulators of antiviral and antibacterial immunity and have inflammatory regulation abilities (Skalny et al., 2020).

\subsection{From administration to bioactivity}

The effects of Pycnogenol $\mathbb{R}$ on endothelial health, microcirculation, platelet reactivity and inflammation have been discussed above. In addition to clinical effects, the mechanisms of action have been also investigated (Grimm et al., 2006; Kim et al., 2008; Kurlbaum et al., 2013; Nishioka et al., 2007; Uhlenhut and Högger, 2012). Pycnogenol $\mathbb{R}$ mainly consists of highly condensed procyanidins (Rohdewald, 2002), and the uptake of these high molecular-weight biopolymers in the gastrointestinal tract is not possible. However, the polymers are metabolised by gut bacteria yielding small molecules, which are actually taken up in the large intestine. After oral intake of single and

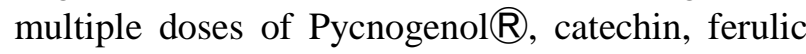
acid, caffeic acid, and taxifolin, a metabolite M1 ( $\delta$-(3,4-dihydroxy-phenyl)- $\gamma$-valerolactone) and further, yet unknown compounds were detected in plasma samples of volunteers (Grimm et al., 2006).

The metabolite M1 is no component of the pine bark extract, but a gut microbial metabolite, which is generated from catechin. The activity of M1 was further investigated and found to dose-dependently inhibit both iNOS (inducible nitric oxide synthase) expression and excessive nitrite production, as it is observed in inflammatory states (Uhlenhut and Högger, 2012). The metabolite M1 was found to be enriched in macrophages, monocytes and endothelial cells by facilitated uptake, thus explaining the rather low plasma/serum concentrations (Uhlenhut and Högger, 2012). 


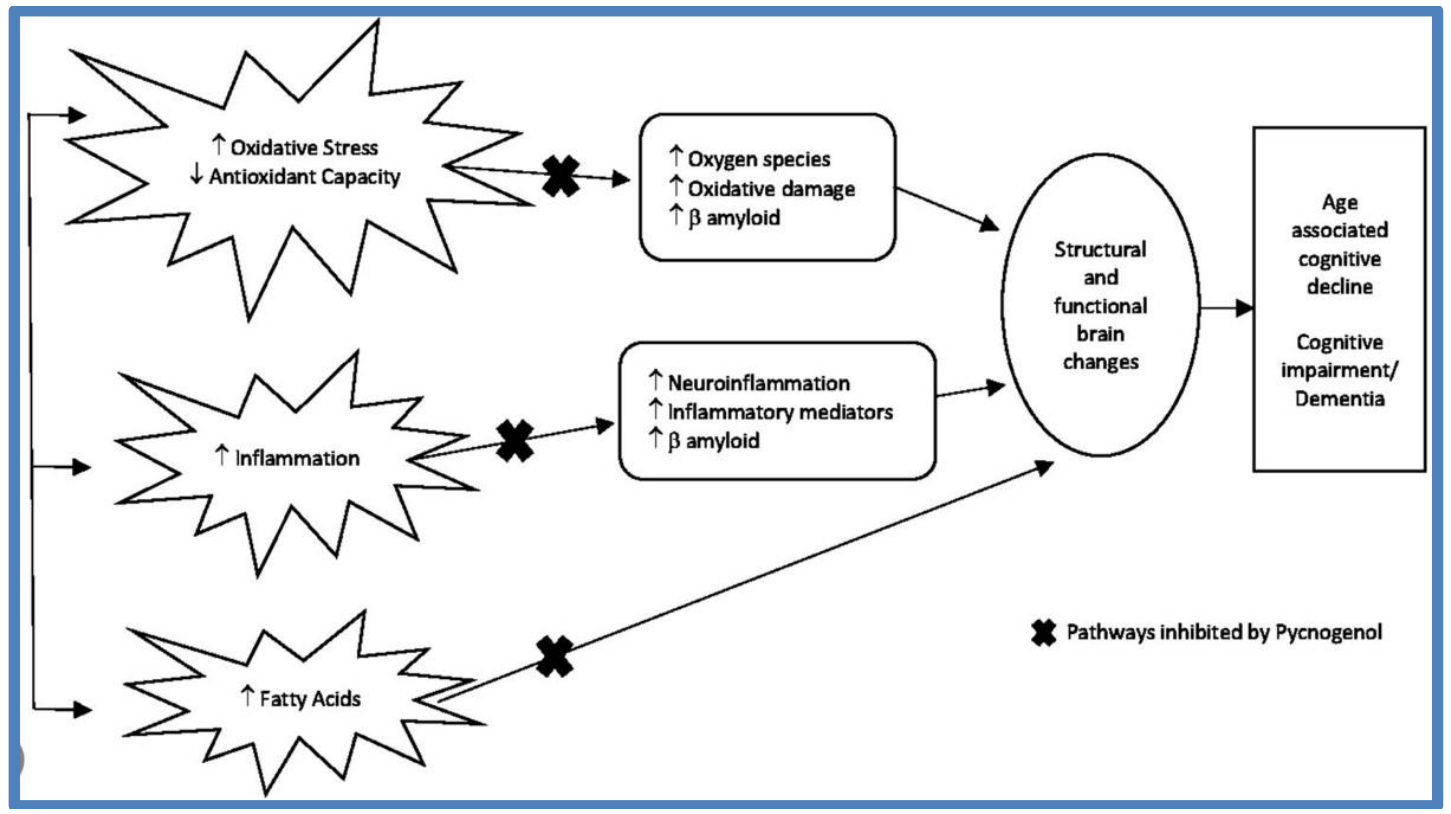

Figure 2. Proposed mechanism of action of PYC as a targeted therapy for preventing cognitive decline.

Further analysis found M1 to be transported into erythrocytes and intracellularly conjugating to a new glutathione adduct, the function of which has yet to be elucidated (Kurlbaum et al., 2013).

With increasing age, inflammation-reduced antioxidant metabolism leading to increased oxidative stress and damage to fatty acids are common mechanisms that over time can impact on the brain causing structural and functional changes culminating in the outcome of ageassociated cognitive decline, cognitive impairment, and/or dementia. PYC potentially inhibits these mechanisms as represented by the $\mathrm{X}$ in the diagram due to its scavenging ability to free radicals and protection of proteins (biomolecules) against oxidative damage (Ansari et al., 2008; Packer et al., 1999; Rohdewald, 2002; Simpson et al., 2019), neuron protection from $\beta$ amyloidinduced apoptosis (Peng et al., 2002; Simpson et al., 2019), anti-inflammatory effects (Lau et al., 2004; Simpson et al., 2019), and reduction of fatty acids (Sivonová et al., 2004).

\section{Conclusion}

Pycnogenol has been proven to possess antioxidant and anti-inflammatory effects along with anti-tumor influence as well. Pycnogenol was concluded to act as an antioxidant agent in different situation including heart stress, cardiovascular system abnormalities, kidney disease and hepatic disorders, so it can be used in combination with other medication such as Methotrexate to abolish its side effects.

\section{References}

Such Ansari, M.A., Keller, J.N., Scheff, S.W., 2008. Protective effect of Pycnogenol in human neuroblastoma SH-SY5Y cells following acroleininduced cytotoxicity. Free Radic Biol Med 45, 1510 1519.

https://doi.org/10.1016/j.freeradbiomed.2008.08.025

Araghi-Niknam, null, Hosseini, null, Larson, null, Rohdewald, null, Watson, null, 2000. Pine bark extract reduces platelet aggregation. Integr Med 2, 73-77. https://doi.org/10.1016/s1096-

\section{0(00)00002-0}

Baluna, R., Rizo, J., Gordon, B.E., Ghetie, V., Vitetta, E.S., 1999. Evidence for a structural motif in toxins and interleukin-2 that may be responsible for binding to endothelial cells and initiating vascular leak syndrome. Proc Natl Acad Sci U S A 96, 3957 3962. https://doi.org/10.1073/pnas.96.7.3957

Belcaro, G., Cesarone, M.R., Errichi, B.M., Ledda, A., Di Renzo, A., Stuard, S., Dugall, M., Pellegrini, L., Gizzi, G., Rohdewald, P., Ippolito, E., Ricci, A., Cacchio, M., Cipollone, G., Ruffini, I., Fano, F., 
Hosoi, M., 2006. Diabetic ulcers: microcirculatory improvement and faster healing with pycnogenol. Clin Appl Thromb Hemost 12, 318-323. https://doi.org/10.1177/1076029606290133

Belcaro, G., Cesarone, M.R., Errichi, B.M., Ledda, A., Di Renzo, A., Stuard, S., Dugall, M., Pellegrini, L., Rohdewald, P., Ippolito, E., Ricci, A., Cacchio, M., Ruffini, I., Fano, F., Hosoi, M., 2005. Venous ulcers: microcirculatory improvement and faster healing with local use of Pycnogenol. Angiology 56, 699-705. https://doi.org/10.1177/000331970505600607

Canali, R., Comitato, R., Schonlau, F., Virgili, F., 2009. The anti-inflammatory pharmacology of Pycnogenol in humans involves COX-2 and 5LOX mRNA expression in leukocytes. Int Immunopharmacol 9, 1145-1149. https://doi.org/10.1016/j.intimp.2009.06.001

Cesarone, M.R., Belcaro, G., Rohdewald, P., Pellegrini, L., Ledda, A., Vinciguerra, G., Ricci, A., Gizzi, G., Ippolito, E., Fano, F., Dugall, M., Cipollone, G., Acerbi, G., Cacchio, M., Del Boccio, G., Di Renzo, A., Stuard, S., Corsi, M., 2006. Improvement of diabetic microangiopathy with pycnogenol: A prospective, controlled study. Angiology 57, 431-436. https://doi.org/10.1177/0003319706290318

Chovanová, Z., Muchová, J., Sivonová, M., Dvoráková, M., Zitnanová, I., Waczulíková, I., Trebatická, J., Skodácek, I., Duracková, Z., 2006. Effect of polyphenolic extract, Pycnogenol, on the level of 8-oxoguanine in children suffering from attention deficit/hyperactivity disorder. Free Radic Res 40 , 1003-1010.

https://doi.org/10.1080/10715760600824902

Devaraj, S., Vega-López, S., Kaul, N., Schönlau, F., Rohdewald, P., Jialal, I., 2002. Supplementation with a pine bark extract rich in polyphenols increases plasma antioxidant capacity and alters the plasma lipoprotein profile. Lipids 37, 931-934. https://doi.org/10.1007/s11745-0060982-3

Drehsen, G., 1999. 20-From ancient Pine Bark Uses to pycnogenol, in: Antioxidant Food Supplements in Human Health. Eds Packer L., Hiramatsu M., Yoshikawa T., San Diego: Academic Press, pp. 311-322.

Enseleit, F., Sudano, I., Périat, D., Winnik, S.,
Wolfrum, M., Flammer, A.J., Fröhlich, G.M., Kaiser, P., Hirt, A., Haile, S.R., Krasniqi, N., Matter, C.M., Uhlenhut, K., Högger, P., Neidhart, M., Lüscher, T.F., Ruschitzka, F., Noll, G., 2012. Effects of Pycnogenol on endothelial function in patients with stable coronary artery disease: a double-blind, randomized, placebo-controlled, cross-over study. Eur Heart J 33, 1589-1597. https://doi.org/10.1093/eurheartj/ehr482

Fitzpatrick, D.F., Bing, B., Rohdewald, P., 1998. Endothelium-dependent vascular effects of Pycnogenol. J Cardiovasc Pharmacol 32, 509-515. https://doi.org/10.1097/00005344-199810000-00001

Grimm, T., Chovanová, Z., Muchová, J., Sumegová, K., Liptáková, A., Duracková, Z., Högger, P., 2006. Inhibition of NF-kappaB activation and MMP-9 secretion by plasma of human volunteers after ingestion of maritime pine bark extract (Pycnogenol). J Inflamm (Lond) 3, 1. https://doi.org/10.1186/1476-9255-3-1

Grimm, T., Schäfer, A., Högger, P., 2004. Antioxidant activity and inhibition of matrix metalloproteinases by metabolites of maritime pine bark extract (pycnogenol). Free Radic Biol Med 36, 811-822.

https://doi.org/10.1016/j.freeradbiomed.2003.12.017

Hanna, V.S., Hafez, E.A.A., 2018. Synopsis of arachidonic acid metabolism: A review. J Adv Res 11, 23-32. https://doi.org/10.1016/j.jare.2018.03.005

Kashevarova, A.A., Nazarenko, L.P., Skryabin, N.A., Nikitina, T.V., Vasilyev, S.A., Tolmacheva, E.N., Lopatkina, M.E., Salyukova, O.A., Chechetkina, N.N., Vorotelyak, E.A., Kalabusheva, E.P., Fishman, V.S., Kzhyshkowska, J., Graziano, C., Magini, P., Romeo, G., Lebedev, I.N., 2018. A mosaic intragenic microduplication of LAMA1 and a constitutional 18p11.32 microduplication in a patient with keratosis pilaris and intellectual disability. Am J Med Genet A 176, 2395-2403. https://doi.org/10.1002/ajmg.a.40478

Kawabe, S., Saeki, T., Yamazaki, H., Nagai, M., Aoyagi, R., Miyamura, S., 2002. Systemic capillary leak syndrome. Intern Med 41, 211-215. https://doi.org/10.2169/internalmedicine.41.211 
Kim, Y.J., Kang, K.S., Yokozawa, T., 2008. The anti-melanogenic effect of pycnogenol by its antioxidative actions. Food Chem Toxicol 46, 24662471. https://doi.org/10.1016/j.fct.2008.04.002

Kurlbaum, M., Mülek, M., Högger, P., 2013. Facilitated uptake of a bioactive metabolite of maritime pine bark extract (pycnogenol) into human erythrocytes. PLoS One 8, e63197. https://doi.org/10.1371/journal.pone.0063197

Lau, B.H.S., Riesen, S.K., Truong, K.P., Lau, E.W., Rohdewald, P., Barreta, R.A., 2004. Pycnogenol as an adjunct in the management of childhood asthma. J Asthma 41, 825-832. https://doi.org/10.1081/jas-200038433

Liu, X., Wei, J., Tan, F., Zhou, S., Würthwein, G., Rohdewald, P., 2004. Pycnogenol, French maritime pine bark extract, improves endothelial function of hypertensive patients. Life Sci 74, 855-862. https://doi.org/10.1016/j.lfs.2003.07.037

Medzhitov, R., 2008. Origin and physiological roles of inflammation. Nature 454, 428-435. https://doi.org/10.1038/nature07201

Mittal, M., Siddiqui, M.R., Tran, K., Reddy, S.P., Malik, A.B., 2014. Reactive oxygen species in inflammation and tissue injury. Antioxid Redox Signal 20, 1126-1167. https://doi.org/10.1089/ars.2012.5149

Nishioka, K., Hidaka, T., Nakamura, S., Umemura, T., Jitsuiki, D., Soga, J., Goto, C., Chayama, K., Yoshizumi, M., Higashi, Y., 2007. Pycnogenol, French maritime pine bark extract, augments endothelium-dependent vasodilation in humans. Hypertens Res 30, 775-780. https://doi.org/10.1291/hypres.30.775

Oliff, H., 2019. Scientific and clinical monograph for Pycnogenol®, 2019 update [WWW Document ] URL https://abc.herbalgram.org/site/SPageServer/ ; jsessionid=00000000.app2011 CE774A9077 BC429D2BDFE66\&pagename $=$ Pycnogenol (accessed 5.31.21).

Packer, L., Rimbach, G., Virgili, F., 1999. Antioxidant activity and biologic properties of a procyanidin-rich extract from pine (Pinus maritima) bark, pycnogenol. Free Radic Biol Med 27, 704724. https://doi.org/10.1016/s0891-5849(99)00090$\underline{8}$
Peng, Q.L., Buz'Zard, A.R., Lau, B.H.S., 2002. Pycnogenol protects neurons from amyloid-beta peptide-induced apoptosis. Brain Res Mol Brain Res 104, 55-65. https://doi.org/10.1016/s0169328x $(02) 00263-2$

Petrassi, C., Mastromarino, A., Spartera, C., 2000. PYCNOGENOL ${ }^{\circledR}$ in chronic venous insufficiency. Phytomedicine 7, 383-388. https://doi.org/10.1016/S0944-7113(00)80059-8

Pütter, M., Grotemeyer, K.H., Würthwein, G., Araghi-Niknam, M., Watson, R.R., Hosseini, S., Rohdewald, P., 1999. Inhibition of smokinginduced platelet aggregation by aspirin and pycnogenol. Thromb Res 95, 155-161. https://doi.org/10.1016/s0049-3848(99)00030-4

Raetz, C.R.H., Whitfield, C., 2002. Lipopolysaccharide endotoxins. Annu Rev Biochem 71, 635-700. https://doi.org/10.1146/annurev. biochem.71.

110601.135414

Rohdewald, P. (Ed.), 2004. "Pycnogenol®, French maritime pine bark extract," in Encyclopedia of dietary supplements, in: Encyclopedia of Dietary Supplements (Online). CRC Press, pp. 547-556. https://doi.org/10.1201/b13959-57

Rohdewald, P., 2002. A review of the French maritime pine bark extract (Pycnogenol), a herbal medication with a diverse clinical pharmacology. Int J Clin Pharmacol Ther 40, 158-168. https://doi.org/10.5414/cpp40158

Ryan, J., Croft, K., Mori, T., Wesnes, K., Spong, J., Downey, L., Kure, C., Lloyd, J., Stough, C., 2008. An examination of the effects of the antioxidant Pycnogenol on cognitive performance, serum lipid profile, endocrinological and oxidative stress biomarkers in an elderly population. $J$ Psychopharmacol 22, 553-562. https://doi.org/10.1177/0269881108091584

Schäfer, A., Chovanová, Z., Muchová, J., Sumegová, K., Liptáková, A., Duracková, Z., Högger, P., 2006. Inhibition of COX-1 and COX-2 activity by plasma of human volunteers after ingestion of French maritime pine bark extract (Pycnogenol). Biomed Pharmacother 60, 5-9. https://doi.org/10.1016/j.biopha.2005.08.006 
Siddall, E., Khatri, M., Radhakrishnan, J., 2017. Capillary leak syndrome: etiologies, pathophysiology, and management. Kidney Int 92, 37-46. https://doi.org/10.1016/j.kint.2016.11.029

Simpson, T., Kure, C., Stough, C., 2019. Assessing the Efficacy and Mechanisms of Pycnogenol ${ }^{\circledR}$ on Cognitive Aging From In Vitro Animal and Human Studies. Front Pharmacol 10. https://doi.org/10.3389/fphar.2019.00694

Sivonová, M., Waczulíková, I., Kilanczyk, E., Hrnciarová, M., Bryszewska, M., Klajnert, B., Duracková, Z., 2004. The effect of Pycnogenol on the erythrocyte membrane fluidity. Gen Physiol Biophys 23, 39-51.

Skalny, A.V., Rink, L., Ajsuvakova, O.P., Aschner, M., Gritsenko, V.A., Alekseenko, S.I., Svistunov, A.A., Petrakis, D., Spandidos, D.A., Aaseth, J., Tsatsakis, A., Tinkov, A.A., 2020. Zinc and respiratory tract infections: Perspectives for COVID-19 (Review). Int J Mol Med 46, 17-26. https://doi.org/10.3892/ijmm.2020.4575

Steigerwalt, R., Belcaro, G., Cesarone, M.R., Di Renzo, A., Grossi, M.G., Ricci, A., Dugall, M., Cacchio, M., Schönlau, F., 2009. Pycnogenol improves microcirculation, retinal edema, and visual acuity in early diabetic retinopathy. $J$ Ocul Pharmacol Ther 25, 537-540. https://doi.org/10.1089/jop.2009.0023

Stuard, S., Belcaro, G., Cesarone, M.R., Ricci, A., Dugall, M., Cornelli, U., Gizzi, G., Pellegrini, L., Rohdewald, P.J., 2010. Kidney function in metabolic syndrome may be improved with Pycnogenol®. Panminerva Med 52, 27-32.
The American Botanical Council, 2019. Scientific and clinical monograph for Pycnogenol (French maritime pine bark extract) Pinus pinaster Aiton subsp. atlantica [Fam. Pinaceae].

Trebatická, J., Ďuračková, Z., 2015. Psychiatric Disorders and Polyphenols: Can They Be Helpful in Therapy? Oxid Med Cell Longev 2015, 248529. https://doi.org/10.1155/2015/248529

Uhlenhut, K., Högger, P., 2012. Facilitated cellular uptake and suppression of inducible nitric oxide synthase by a metabolite of maritime pine bark extract (Pycnogenol). Free Radic Biol Med 53, 305313.

https://doi.org/10.1016/j.freeradbiomed.2012.04.013

Weichmann, F., Rohdewald, P., 2020. Projected supportive effects of Pycnogenol $(\mathbb{R}$ in patients suffering from multi-dimensional health impairments after a SARS-CoV2 infection. Int J Antimicrob Agents 56, 106191. https://doi.org/10.1016/j.ijantimicag.2020.106191

Xia, Y.F., Zhang, J.H., Xu, Z.F., Deng, X.M., 2015. Pycnogenol, a compound isolated from the bark of pinus maritime mill, attenuates ventilator-induced lung injury through inhibiting NF- $\mathrm{BB}$-mediated inflammatory response. Int J Clin Exp Med 8, 1824-1833.

Zibadi, S., Rohdewald, P.J., Park, D., Watson, R.R., 2008. Reduction of cardiovascular risk factors in subjects with type 2 diabetes by Pycnogenol supplementation. Nutr Res 28, 315-320. https://doi.org/10.1016/j.nutres.2008.03.003 